\title{
Mitos, ritos, utopías, idolatrías, alienación y fetiches de la educación
}

\section{Myths, rites, utopias, idolatries, alienation, and education fetishes}

\author{
Guillermo Hernández Orozco* \\ Francisco Alberto Pérez Piñón*** \\ Jesús Adolfo Trujillo Holguín***
}

\begin{abstract}
*Profesor investigador de la Universidad Autónoma de Chihuahua (México). Es doctor en Ciencias Pedagógicas por el Instituto Superior Pedagógico Enrique José E. Varona (Cuba). Entre sus publicaciones recientes están: "José Joaquín Calvo López, fundador del Instituto Científico y Literario, hoy Universidad Autónoma de Chihuahua" en IE Revista de Investigación Educativa, Vol. 8, No. 14 (2017); Debates por la historia (Cinco tomos). Reconocimiento Eduardo Flores Kastanis a la Investigación Educativa 2018; Perfil Prodep y del Sistema Nacional de Investigadores Nivel 1. Su tema de interés es la historia e historiografia de la educación. Correo electrónico ghernand@uach.mx

(iD) https://orcid.org/0000-0001-7287-8240
\end{abstract}

**Profesor investigador de la Universidad Autónoma de Chihuahua (México). Es doctor en Ciencias Pedagógicas (Cuba). Entre sus publicaciones recientes están: "Apuntes para una historia posmodernista" en Espacio abierto vol. 25, n.4 (2016); capitulo de libro "La hacienda de coyotillos, un acercamiento a los contenidos educativos", en Acercamientos a la historia de la educación, diálogos actores y fuentes en la construcción del conocimiento histórico (2017). Desarrolla la línea de investigación Historia e Historiografia de la Educación. Cuenta con reconocimientos Prodep y del Sistema Nacional de Investigadores Nivel 1. Es miembro de la Sociedad Mexicana de Historia de la Educación, del Consejo Mexicano de Investigación Educativa y de la Red de Investigadores Educativos Chihuahua. Correo electrónicoaperezp@uach.mx

(iD) https://orcid.org/0000-0003-4316-6484

***Profesor de la Universidad Autónoma de Chihuahua (México). Es doctor en educación por la Universidad Autónoma de Chihuahua (México). Entre sus publicaciones recientes están: Debate legislativo y educación. El artículo tercero a cien años de la Constitución Política de 1917 (coord.) (2018). Cuenta con reconocimiento al perfil Prodep y del Sistema Nacional de Investigadores Nivel 1. Es socio del Consejo Mexicano de Investigación Educativa, de la Sociedad Mexicana de Historia de la Educación y de la Red de Investigadores Educativos Chihuahua. Sus temas de interés son la historia e historiografia de la educación y formación de maestros. Correo electrónico jatrujillo@uach.mx

id https://orcid.org/0000-0002-6738-1878

\section{Historial editorial}

Recibido: 03-junio-2018

Primera revisión: 12-junio-2018

Segunda revisión: 13-septiembre-2018

Aceptado: 22-septiembre-2018

Publicado: 31-octubre-2018 
Mitos, ritos, utopías, idolatrías, alienación y fetiches de la educación

\title{
Resumen
}

Este artículo pretende mostrar diversas concepciones que implica la educación, pero que no se explicitan normalmente en los análisis que se realizan. Existen visiones ocultas que requieren de una segunda mirada para explicárselas y que constituyen comportamientos culturales de la sociedad.

Palabras clave: Mitos, utopías, fetiches, alienación, educación.

Myths, rites, utopias, idolatries, alienation, and education fetishes

\begin{abstract}
This paper attempts to explain diverse implied educational beliefs that are not overtly disclosed in educational analysis. Culturally biased prior beliefs on education require further examination.

Keywords: Myths, utopias, fetishes, alienation, education.
\end{abstract}




\section{Introducción}

La luna tiene dos caras, una no la vemos a simple vista. Este artículo tiene como objetivo plantear aspectos de la otra cara de la educación.

La calidad de la educación se encuentra ligada al desempeño que los estudiantes tengan en su trabajo cotidiano, más allá de los discursos reiterativos de autoridades, maestros y alumnos.

Alcanzar alto nivel de desempeño es más difícil -mucho más difícil-, más complejo que cursar ciclos escolares: primaria, secundaria, preparatoria, licenciatura, maestría o doctorado. Va más allá de conocer teorías, plantear objetos de estudio, encuadrar tesis y obtener altas calificaciones al transitar por el plan de estudios. Eso dicen.

Cada estudiante nace inserto en una cotidianeidad cultural, en ello mama, junto con la leche materna, las aspiraciones, frustraciones y esperanzas de su vida. Amasamos con el sudor, el polvo cultural recogido en el camino, en nuestro camino y así fraguamos, casi inexorablemente el rol de nuestra vida. Ella nos condiciona y explica nuestra propia identidad.

El contexto, la realidad social donde nacemos, donde crecemos y donde se desempeña cada persona, es una realidad plural, contradictoria, de encuentros y desencuentros, coincidencias, divergencias, colisiones, circulación de ideas, tolerancia y concertación. Aleación múltiple de lo individual y lo social.

El análisis de una hoja proporciona la identidad de todos los árboles de la especie. El análisis de un estudiante no. Conociendo quién es el bueno, el que sabe estudiar, el que reúne más gramos de dieces y títulos, no puede servir de modelo para otros. Cada quien tiene que buscar su 
propia identidad, su propio estilo, construir su yo educativo existencial en el transcurso de su vida.

Lo que el estudiante exprese verbal y por escrito, es más efecto de su largo camino cultural recorrido, ahí desde el vientre materno, desde oler el sudor de la familia, de ver día a día los polvos surgidos de las angustias de la colonia. De las esperanzas amalgamadas con canciones de cuna y gritos estridentes de conflictos personales y familiares, pintados noche a noche con los claroscuros de la vida cotidiana, al ritmo cadencioso o a contracanto del teatro real de actores conocidos, con papeles estereotipados en que se vuelven tíos, abuela, novia, vecino y Don José, el de la tiendita de la esquina. Todos presentando la función diaria en el cual somos protagonistas, estelar o no, sobre todo en el espacio laboral, donde se cambia de escenario, pero se sigue de actor. Así se transita por la vida.

\section{Mito}

Mito es el deseo de alcanzar un ideal que en la realidad misma es imposible conseguir. Es un conjunto de creencias para eludir explicaciones de realidades complejas. Por ejemplo, que todos los estudiantes que obtengan un grado, llegarán mágicamente a ser buenos profesionistas.

Es decir que los estudiantes sean lo que deben ser y no lo que son, que posean los atributos que el planteamiento del plan de estudios les prometió: expertos en su área, que lleguen a ser, si peregrinan hasta el santuario, si cursan todas las materias, alcanzarán el milagro; ser buenos profesionistas, reconocidos por la sociedad y alcanzarán éxito laboral. 
El mito es una realidad psíquica, porque la estructura interpretativa del sujeto, al ir construyendola, se convierte en su criterio, es su lente con que mira la realidad, sirviéndole de referente para juzgar lo que sucede, su entorno. Los mitos, como las estructuras interpretativas requieren de tiempo para la asimilación y acomodación en el pensar del estudiante, por eso deben cursarse en años los ciclos educativos, no en función de su capacidad y demostración de competencias para aquellos que pueden acortar los ciclos. Entrando a un túnel curricular, debe atravesarse todo.

Mito es un pensar colectivo que no puede ser refutado racionalmente en la medida que está en consonancia, que coincide con el consenso del grupo: escuela, contexto familiar, laboral, sociedad toda, ya que no se tiene conciencia de que es un mito. El mito es el lenguaje de la acción.

Aprendido un pensar mítico, no queda más opción que ponerlo en práctica. Realizar el proceso educativo donde se apuntalan mitos, es condición sine qua non. Así todos los estudiantes, maestros y autoridades educativas, hablarán el mismo lenguaje mítico, contarán con la misma estructura interpretativa.

El origen del mito surge ante la pérdida de fe en alcanzar utopías ante la descalificación, porque los modelos sociales seguidos hasta ahora pierden el hechizo de la modernidad. Lo que hace la educación es formar profesionistas y nos dicen que no tiene calidad, que no sirve, nos descalifican.

La modernidad por ser moderna, es eficaz.

El mito de que los estudios transforman, se origina por fuerzas inconscientes, que al no encontrar explicaciones a lo complejo, opta por explicaciones fáciles, creando un nuevo mito, fruto del deber ser, de la 
incapacidad explicativa y se deja en manos de los dioses para que decidan.

Los proyectos educativos no funciona sino hasta que el consenso del grupo "quiera” el mito: institución y diseñadores se apegan a políticas y encuadres nacionales de posgrado. La escuela avala su funcionamiento para que responda a esa "necesidad social", para eso están las instituciones, para responder a las necesidades educativas de la sociedad, donde inconscientemente contribuye así a la construcción social de mitos: eso sí, en nombre de la calidad, en nombre de la ciencia y el desarrollo de la nación.

Cursar una licenciatura y posgrado tiene también como origen la amenaza externa que pone en peligro la estabilidad laboral del estudiante, la existencia y desarrollo del académico, sin grado académico no tiene acceso a alto status profesoral. Otros actores comienzan a invadir el espacio del académico, nos descalifican y alguien descalificado no tiene derecho a nada; está en entredicho.

Es necesario que el profesional de la educación, el estudiante se inserte en una sociedad moderna, para que se le reivindique, relegitime, recalifique, o se queda en el andén, sin viajar en el tren en vagones de primera, por no contar con el boleto, con el grado de abordaje.

\section{8}

\section{Fetiche}

Fetiche es un objeto al que se le asignan poderes que no tiene.

El origen, donde radican sus poderes, es mágico, es decir, está fuera de toda razón. Por lo tanto, no hay que buscarle explicación, simplemente hay que creer en que tiene el poder, utilizar el fetiche en sustitución de 
la explicación, así de simple. El profesional de la educación será mejor. Nada de comprobar sólo hay que cumplir el rito para alcanzar el grado.

El ejercicio educativo es un espacio social que ha ido cobijando y construyendo fetiches. Son tantos y tan abundantes que convivimos a diario con ellos. Ni siquiera nos damos a la tarea de diferenciar los que son, de los que no son.

Cada programa educativo, más que formar para el desarrollo en la sociedad, apuntala y recrea fetiches: actores de la educación, profesores, directores de tesis, tutores, autoridades, teorías, estructuras de tesis, metodologías, coloquios, artículos que se escriben. Uno o varios se invocan como fetiches hacedores de milagros.

Nuestra cultura occidental, nuestra cultura cristiana es profundamente fetichizada. Es decir, la vida del individuo depende de la divinidad, ella a su arbitrio puede favorecer o castigar personas y pueblos a su antojo, por eso hay que estar bien con el dios-fetiche, por eso hay que invocarlo. Nuestro futuro como maestros, depende del dios-título, que a su suerte está echada nuestra vida. Hay que estar bien con el "hacedor de milagros", con el proceso educativo, sea o no racional, no hay que cuestionarlo.

La relación ancestral cultural hombre-dios, implica poner en manos de dios, del fetiche, de la institución educativa nuestra suerte, nuestra existencia estudiantil. Implica poner en manos del otro; de la escuela, de la universidad, nuestro futuro existencial. Consiste en renunciar a ser nosotros los "artífices de nuestro propio destino" para dejar en el fetiche nuestra suerte.

El primer espacio social, formal, donde se construyeron y alimentaron los fetiches, en nuestra cultura occidental, fueron las iglesias, luego, las escuelas; hoy el gran espacio lo constituyen los medios de 
comunicación: prensa, radio y televisión, las redes sociales vía electrónica.

El sacerdote, mediador entre dios y los hombres, fue substituido por el maestro, mediador entre los dioses: teorías que deben ser interpretadas solo por los ungidos para que los "humanos" tengan acceso, la entiendan "cómo debe ser". El profesor media, explica desde dónde abordar las teorías y qué deben hacer para seguir en armonía en el proceso de los estudios, cualquiera que sea el nivel. El maestro es el sumo intérprete, los demás humildes aprendices, al fin alumnos.

Los principales fetiches que el maestro crea, alimenta, valida y apuntala a diario son:

- La educación profesional es concebida como un fetiche cuando se le asigna el poder de conducir certeramente a la aplicación y producción de conocimiento profundo, que solo en ese santuario académico del doctorado se puede lograr. Poder que no tiene.

- La discusión de ideas una vez realizada entre estudiantes, presidida por el doctor ungido para el caso, ya se puede invocar, cada participante o en coro y se fetichiza, cosifica, pero se tiene que creer firmemente en que es hacedora de milagros. Por algo se le invoca.

- A los académicos se les asigna el rol de fetiches, en la medida en que se hace depender el éxito educativo, de que se produzca el milagro de que los estudiantes-maestros se conviertan en doctores-investigadores exitosos y que culminen no solo con el grado de doctores sino también en el Sistema Nacional de Investigadores. También a teorías y estructuras validadas de tesis. 
- El profesor es concebido socialmente como un fetiche, cuando el Estado, las organizaciones, las familias y la universidad depositan en él la función de construir un doctor crítico, creador, investigador, consciente, conocedor de la verdad, justo, libre, democrático, culto, solidario y transformador de la realidad. Ante la imposibilidad de la sociedad de alcanzar utopías, estados ideales, aceptar realidades, se acude a la educación-fetiche para que sea quien mantenga la esperanza de alcanzar el milagro. Total, si no sucede en un tiempo determinado, los profesores siguientes, más profesionales, con estudios profundos, con grados doctorales, se encargarán de explicar, por qué no se han alcanzado los ideales planteados y propondrán nuevas reformas. Cuando el fetiche, el maestro estrella se desgaste, basta cambiar por otro profesional, cuando se desgaste San Martín de Porres, cambiamos a San Judas.

- El alumno se convierte en autofetiche al convertirse en cosa, el objeto de la educación que deja al otro, al maestro, a la institución que haga el milagro de transformarlo. Él sólo cumple los ritos. Peregrina durante los semestres por los estudios asignados, hace tareas, asiste a coloquios, participa en discusiones, escribe, habla, lee, invoca teorías, plantea marcos teóricos, problemas, estados del conocimiento, objetos de estudio, metodologías, conclusiones que a manera de rosario enlaza como debe ser, los exhibe e invoca como hacedores de milagros.

La pérdida del hechizo del fetiche hace que los estudiantes los deslegitimen y de esa manera pierden credibilidad social; académico sin nivel doctoral poco vale hoy en día. 
Ante la pérdida de fe en el fetiche, se busca otro, más efectivo, más moderno, más profesional, con mayor nivel académico. Se construye otro mito para sustituir el actual, ante la imposibilidad de aceptar la realidad tal como es, se culpa al sistema, a los métodos que utiliza, a la falta de nivel académico de sus maestros, a los apoyos de las instituciones educativas. En suma, el causante de los males en el proceso educativo, son los otros, no el propio estudiante.

En el caso del sistema educativo la solución consiste en cambiar el modelo, hacer una reforma educativa, proponer otro proyecto "modernizador", otro plan de estudios, es decir, construir otro mito para que todo siga igual.

Después de todo, tenemos una sociedad fetichizada, apuntalada por la educación, quien contribuye a crearlos, alimentarlos y dimensionarlos, según que el momento histórico lo requiera. Así crea, alimenta y cosifica sus fetiches.

Cada título educativo es un fetiche en la medida en que lo cosificamos y se convierte en objeto mágico, hechicero, tanto el programa como las teorías, tesis, directores de tesis, tutores, autoridades, encuentros.

La educación es un fetiche a quien le asignamos poderes que no tiene, ni necesita tenerlos, basta creer que los tiene.

\section{Rito}

Es un conjunto de prácticas que se realizan en ceremonia para invocar divinidades, conocer lo desconocido, agradecer eventos difíciles o validar existencias. 
Es condición indispensable ejecutarlo, para que el rito produzca el efecto esperado. Para que valga.

Es un conjunto de prácticas hechiceras que tienen que ser presididas por un ungido y mejor si se realiza en espacios sagrados.

La educación está conforma por ritos que se practican en la peregrinación por preescolar, primaria, secundaria, preparatoria, licenciatura y maestría. Es decir, ese recorrido asegura que las acciones rituales del espacio educativo, ya están internalizadas por los estudiantes. Les son naturales.

La universidad es el gran espacio académico y se vuelven sagrados los doctorados como el máximo grado que se ofrece. El director de tesis es ungido, tiene el grado ya de doctor, pero no es cualquiera, también está ungido por el Sistema Nacional de Investigadores, perteneces a Cuerpos Académicos consolidados. Por lo tanto, se requiere realizar en ceremonia un conjunto de prácticas hechiceras, que se materializan en tesis, sobre todo.

El proceso de cursar una licenciatura se concibe como una relación mágica entre el sujeto y el objeto, entre el plan de estudios y el estudiante, donde se espera que con seguir el rito: aceptación, entrega de documentación, aceptación como becario, asistir a eventos, escribir, desmenuzar teorías, elegir categorías, pasar semestre a semestre. Habiendo cumplido todos los ritos debe suceder el milagro: transformar al aprendiz en experto de alto nivel. Lo mágico de estar en un santuario educativo es, por encima de todo, seductor. Entre más se sufra en el trayecto de cursar estudios, más meritorio es ante la mirada de los dioses. 


\section{Hechizo}

Se adquiere en ceremonia para que el sujeto sea poseído por algún ente que tiene poderes sobrenaturales, que deja de ser él para pasar a comportamientos conformados desde fuera, desde quien lo posee.

Es un estado de la persona que no se comporta como los otros.

El poseído actúa fuera de lo normal y eso lo legitima como hechizado para que los demás lo comprendan, es decir que no es él, es el otro, que como desconocido no se le cuestiona, no está presente la lógica de los normales porque es anormal, implica cambiar las reglas del juego. Un asunto clave es que los demás se dan cuenta de su comportamiento anormal, hechizado, él no, lo que lo libera de racionalidades.

El hechizado habla diferente, utiliza palabras, conceptos inentendibles para quienes lo escuchan, pero lo remiten a que es una persona por encima de las personas normales. Por ejemplo, habla "arameo" cuando nadie lo entiende, necesita conocerlo, basta creer que está poseído, no por demonios sino por la educación, por la ciencia, como sucede con los hechizados académicos.

Por lo tanto, las personas con educación superior y más de posgrado, ya están hechizados, por eso dicen lo que dicen, hablan lo que hablan y se comportan como se comportan. El hechizo es seductor.

\section{4}

\section{Hipnotismo}

Acto por el cual se transita de un estado consciente a otro seminconsciente. El hipnotizado pasa de ser responsable de sus comportamientos a depender del hipnotizador. 
En el acto de hipnotismo hay dos actores, el hipnotizador quien ayuda, manipula y conforma ambientes para que suceda la hipnotización y el hipnotizado, quien acepta serlo.

El hipnotismo acontece, pero el proceso psicológico todavía tiene mucho camino que recorrer. Pero de que sucede, sucede. Nadie puede ser hipnotizado sin su voluntad. Pero hay múltiples procesos psicológicos para convencer al hipnotizado que es bueno para él, que es una experiencia buena. Para hipnotizar a una persona puede ser en 20 minutos, dependiendo del hipnotizador y del hipnotizado. Este proceso es muy utilizado en agrupaciones religiosas en congresos, reuniones de un día, tres o cinco. Invocan que verán, oirán, tocaran, sentirán lo que el hipnotizador quiera.

Más si la reunión hipnotizadora es de tres años de preescolar, seis de primaria, tres de secundaria, tres de preparatoria, cuatro de universidad, dos de maestría y tres de doctorado. Sí, la educación es un espacio hipnotizador para que los estudiantes se comporten como el Estado, se comporten hipnotizados en nombre de la ciencia, la cultura, el bien común, el país u otra invocación. Los hipnotizadores necesitan 20 minutos, cinco días, la educación requiere años.

\section{Iconoclasta}

En la edad media, en la cultura cristiana, surgieron los iconoclastas. Es decir, los destructores de imágenes. En esencia, no adorar iconos, es decir imágenes.

Quizá, el Moisés bíblico fue el primero que al bajar supuestamente del monte Sinaí, cuando Yavé le proporcionó los diez mandamientos y entonces cuando adoraban los judíos la representación de dios, 
materializado en un becerro de oro, arremetió destruyéndolo. Eso es iconoclasta, cualquiera que adore imágenes. Por ejemplo, en las dependencias gubernamentales aparece la figura en turno, presidente, gobernador, presidente municipal, rector o director de la institución, escuela o dependencia.

La educación es adoradora de íconos: Piaget, constructivismo, didáctica, investigación, licenciaturas y posgrados y mil más.

Quien atenta contra un ícono en una cultura concreta no solo es descalificado, sino es perseguido. ¿Quién cuestiona a la educación como el medio de movilidad social, de progreso, de status cultural, social y conciencia existencia?, para empezar.

Es fundamental no confundir el título adquirido, el ícono, que la conciencia existencial. No basta con colgar el título con el mejor marco en la sala. Es una espada de dos filos. A veces vale más no exhibir título alguno y que lo crean a la persona tonta y exhibirlo y que ya nadie lo dude.

\section{Utopía}

Es un ideal que en la realidad es imposible alcanzar. La utopía se crea cuando la anterior se desgasta y se pierde la esperanza de ser alcanzada.

El desencanto del egresado de licenciatura, al no alcanzar el éxito a su esfuerzo, ya sea de reconocimiento o económico, en el tiempo que se fijó, produce pérdida de fe, pero las personas no pueden vivir sin esperanzas, sin perseguir utopías, por eso es necesario crear otra, para que así se mantenga en movimiento, en persecución de liebres inatrapables. 
Utopía es una ilusión mental, producto del pensar alejado de la realidad. De usar las teorías creyendo que la realidad debe ser como la teoría y no al revés, la realidad es como es y la teoría sólo sirve para explicar en parte, la realidad.

La educación en concertación con instituciones, crean utopías, por ejemplo, maestrías y doctorados, cuyos logros totales, son una utopía.

La utopía funciona como simplificadora de la compleja realidad académica y éxito laboral, donde su logro depende en menor medida del estudiante, de su preparación y más de otras variables circunstanciales, culturales, tradicionales, empresariales, políticas y en todo caso sociales.

\section{Idolatría}

Consiste en la adoración de fetiches, cosificando en objeto a la divinidad y dejando fuera de la racionalidad la acción. Es una manera de renunciar a comprender la compleja fundamentación del origen y posibilidades del ídolo. Es una manera de renunciar a asumir la responsabilidad de comprender y dejar en el otro la resolución de los problemas. En vez de invocar a la suerte, se invoca al ídolo hechicero.

La idolatría se muestra en desempeños existenciales y se ejerce de manera individual, favorecida por comportamientos colectivos. Su fundamentación radica en la fe, no en la racionalidad.

La Santa Muerte protege a los sicarios, San Juditas solo a los que peregrinan hasta su santuarios. El Santo Señor del Tizonazo a los agricultores. Santoral es el conjunto de personas ungidas que sirven de mediadores entre dios y los humanos. 
La educación tiene su santoral manifestado en teorías validadas, en marcos teóricos consistentes, en metodologías comprobadas, en investigaciones que producen conocimiento, en artículos arbitrados. Todos ellos invocados, sirven de mediadores para que el dios ciencia y los estudiantes vivan en armonía.

El estudiante y los profesores tiene como una de sus tareas principales construir mitos y utopías erigidos con fetiches cuando otros títulos y grados se desgastan, cuando pierden su magia, el hechizo de alcanzar verdades. Por ello, el estudiante tiene que construir sus mitos con fetiches creados en sus sueños en que se sustenta el andamiaje de sus idolatrías.

La idolatría tiene como fundamentos la magia. Es un pensar colectivo. Su origen radica en la simplificación de la complejidad. El idólatra no tiene que comprender problemas y soluciones, solo realizar el rito mágico y tener fe en su solución.

La educación es objeto de idolatría en la medida que los conformadores de diseños curriculares creen en los mismos supuestos; directores, coordinador, cada maestro, y sobre todo cada uno de los estudiantes. Si no hay una creencia colectiva no se idolatra, sino es locura de la persona.

Los doctorados no son programas cualquiera, son un objeto sagrado al ser certificado como el máximo nivel académico que ofrecen las universidades. Por ello se idolatran.

\section{Camaleones}


Los programas educativos son camaleónicos, según cada tiempo, cada contexto, cada reforma, adoptan el nuevo color, las nuevas estrategias, las nuevas políticas que como los camaleones se adapta a las características del contexto, cambia de apariencia. Es la apariencia la que cambia, el camaleón es el mismo. Los estudiantes universitarios egresarán con nuevo grado, pero en esencia serán lo mismo.

La finalidad de cambiar el color de la piel, es camuflarse.

Universidad, catedráticos, instalaciones, estudiantes, teorías, son los mismos en cada reforma, pero se cambia de piel.

¡Camaleón que no cambia, es lagartija, y nadie quiere ser lagartija, si se quiere peñasqueada, pero lagartija al fin!

\section{Estratificación}

Es una capa que determina la posición que guarda con relación a otra. En el caso del sistema educativo la solución consiste en hacer reformas educativas, proponer otro proyecto "modernizador", cambiarle la piel al camaleón para que todo siga igual.

La función que cumple la educación, en gran medida es la de estratificadora social de los habitantes de un país, de un estado, de una ciudad. Son clasificados entre los que saben o no leer, los que solo tienen educación básica, entre los que tienen educación superior. Entre los que "saben" y los que no. Entre los egresados de un programa de calidad y una "Universidad patito". Aunque el desempeño real no necesariamente se refleje en el trabajo. Hoy la estructura social, laboral, de poder, necesita diferenciar para validar complejos entramados de 
discriminación, no por el color, creencias, sexo, sino por los estudios realizados. Si, la educación también es estratificadora social.

\section{Alienación}

Alien quiere decir ajeno. Alienado es una persona poseída por alien. Es la ausencia de conciencia. Surge ante la pérdida de fe, de fe en alcanzar utopías hechas de fetiches y mitos, realizando ritos hechiceros que en conjunto se convierten en el andamio desde donde se mira la realidad.

La alienación es un pensar común, que los contextos culturales han creado para encapsular a las personas desde su nacimiento hasta su muerte y reproducirse culturalmente.

El pensar alienado pone como referente de su validez el pensar alienado de los otros que le rodean. Sociedades alienadas, engendran personas alienadas, a veces expresadas como voluntad divina o quehacer científico.

Los posgrados son espacios de alienación, en nombre de la desalienación, en la medida que su estructura, planes de estudio, mitos, ritos, fetiches, hechizos, idolatrías se convierten en el trabajo académico. Cumplir normas por encima de todo.

Construido un pensar alienado, se comprende, califica y redimensiona todo, desde la alienación.

Quien está desalienado, debe estar consciente que le rodea un contexto alienado y como tal, está acosado día a día, pensar a pensar, comportamiento a comportamiento, para que transite por su proceso educativo de manera alienada. 
Se tiene que tener consciencia de que se vive en un mundo académico alienado. Un error alienado es enfrentar a actores alienados para desalienarlos, son ejército y no se debe combatir contra miles. Esa es su vida. El reto de cada estudiante y maestro es pensar, ser y actuar desalienado.

\section{¿Qué hacer?}

Alejarse del sentido común que cosifica, fetichiza, ritualiza, aliena, mitifica, hechiza, hipnotiza y utopiza el proceso educativo, pero sobre todo existencial.

Tener conciencia de que la alienación es el reto a vencer para no convertir a la educación en espacio donde fragua cada estudiante su estructura interpretativa alienada. Lo opuesto es la conciencia.

Quitarse la máscara de hechiceros científicos, bajo la cual se encuentra la amenaza constante de la cultural hecha de fetiches, hechizos, mitos, ritos y utopías para mantener el reto desalienante.

En el proceso en actores educativos convertirse en iconoclastas, destruyendo imágenes que cosifican la educación. Destruir la imagen, la representación, para reconocer la esencia.

Mantenerse alerta para no esterilizar teorías. No creer en santorales de teorías.

Alejarse de mafias académicas. Cuestionar sus planteamientos.

Desandar caminos alienantes. Realfabetizarnos para reinterpretarnos a nosotros mismo y al conjunto de variables que constituyen nuestro yo cultural alienante, que condiciona nuestro desempeño existencial. 
Tener conciencia de cómo hemos construido nuestra identidad y enfrentar al pulpo, cuyos tentáculos son fetiches, mitos, ritos, idolatrías, utopías, alienaciones, hechicerías e idolatrías y que nosotros somos protagonistas, para bien o para mal.

\section{Conclusión}

En fin, nadie puede vivir sin mitos, fetiches, ritos, hechicerías, hipnotismos, alienaciones, camaleones, idolatrías y utopías, las personas como tú y yo, ¿lo podremos hacer?

Este artículo se publica bajo una licencia de Creative Commons Reconocimiento-NoComercial 4.0 Internacional, y puede ser usados gratuitamente para fines no comerciales, dando los créditos a los autores y a la revista.

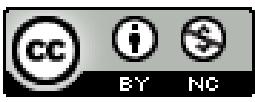

